\title{
Infracentimetric HER-2 positive breast tumours-review of the literature
}

\section{Danilo da Fonseca Reis Silva ${ }^{1}$ and Joana M Ribeiro ${ }^{2}$}

${ }^{1}$ Instituto do Câncer do Estado de São Paulo - ICESP - Faculdade de Medicina da Universidade de São Paulo, Av. Doutor Arnaldo, 251 - Cerqueira César, São Paulo - SP 01246-000, Brazil

${ }^{2}$ Breast Unit, Champalimaud Clinical Centre, Av. de Brasília, s/n, Lisbon 1400-038, Portugal

Correspondence to: Joana M Ribeiro. Email: joana.ribeiro@fundacaochampalimaud.pt

\begin{abstract}
Breast cancer is the most common malignant neoplasm in the world among women. As a result of the dissemination of population screening programmes, about half of non-metastatic breast cancers are now diagnosed at stage I. 10-15\% of T1abN0 tumours over-express human epidermal growth factor (HER-2). These tumours have a globally excellent prognosis, however, treatment with chemotherapy and/or targeted therapy may further improve outcomes in selected cases. In this article, we will review studies with information on prognosis and benefit of adjuvant therapy for T1abNO HER-2+ breast cancer.
\end{abstract}

Keywords: breast cancer, infracentimetric, HER-2 positive breast cancer

ecancer 2015, 9:593 DOI: 10.3332/ecancer.2015.593

Copyright: (c) the authors; licensee ecancermedicalscience. This is an Open Access article distributed under the terms of the Creative Commons Attribution License (http://creativecommons.org/licenses/by/3.0), which permits unrestricted use, distribution, and reproduction in any medium, provided the original work is properly cited. 


\section{Introduction}

Breast cancer is the most common malignant neoplasm in the world among women, representing approximately $25.2 \%$ of new cases of cancer [1]. Data from SEER (the Surveillance, Epidemiology, and End Results Programme) indicate that approximately 12.5\% of American women will have this diagnosis at some point in their lives [2]. In the last few decades, there has been an increase in the proportion of cases diagnosed at earlier stages, such that stage I tumours currently represent nearly half of the cases of non-metastatic disease [3]. According to SEER between 1990 and 1998, there was a 15\% increase in the incidence of T1 tumours (0-2 cm) in the United States (from 143.5-163.5 per 100,000) [4], which is mainly attributed to the detection of non-palpable tumours through the dissemination of population screening programmes with mammography [3, 4].

The overexpression of Human epidermal growth factor-2 (HER-2+) is found in about $20 \%$ of breast tumours and is associated with worse survival rates, especially in the population with positive lymph nodes [5-7]. Among infracentimetric tumours (T1ab), only 10-15\% are HER-2 positive [8-10], which may reflect the increased aggressiveness of these tumours, as they are frequently diagnosed at more advanced stages.

Globally, it is considered that patients with breast cancer of less than $1 \mathrm{~cm}$ have a good prognosis, however, until recently most series did not contain information regarding HER-2 status and the adjuvant therapeutic clinical trials focused on patients with HER-2+ breast tumours excluded those patients [11-15]. In this article, we will review the retrospective and prospective studies as well as the meta-analyses with information relating to the prognosis and therapeutic impact of chemotherapy and/or anti-HER-2 targeted therapy among patients with T1ab tumours.

\section{Breast carcinoma T1ab HER-2+: information on prognosis}

Most studies focused on patients with T1ab breast cancer without lymph node involvement have suggested that these patients, overall, have an excellent prognosis, having a breast cancer specific survival at ten years greater than 95\% [16-18]. However, not all studies were consistent in terms of the reported survival rates [19-21]. The discrepancy observed is probably related to the intrinsic limitations and heterogeneity of the studies which assessed this issue, namely: heterogeneity of the adjuvant systemic treatments used, different techniques and definitions of HER-2 status, reduced sample sizes, and different methodologies used (for example, most studies used different metrics for survival-while some reported disease-free survival (DFS), others recurrence-free survival (RFS)—similar to DFS, but excluding new primary cancers whether of the ipsilateral or the contralateral, while others used breast cancer specific survival (BCSS) and/or distant DFS (DDFS) (Table 1) [8, 9, 20-24].

One of the first studies which analysed the prognosis for infracentimetric tumours assessed a population of 242 patients with lymph node negative breast cancer, of which $19 \%$ were HER-2+ tumours, versus $83 \%$ with HER-2 negative (HER-2-). The RFS at two years was $94 \%$ versus $83 \%$ for HER-2- and HER-2+ tumours respectively ( $p<0.05)$. In this study, for the population of infracentimetric tumours, the HER-2+ status was an independent variable for prognosis with a relative risk of recurrence of 4.6 (confidence interval (Cl) 95\% 1.0-20.6) and death of 11.1 (CI 95\% 1.0-122.8) when comparing HER-2+ with HER-2- tumours [23]. Likewise, in 2003, a study by a Finnish group included 852 stage I patients-36.7\% of these T1ab-demonstrating a relative risk of 2.6 in DDFS at nine years for HER-2+ tumours when compared with HER-2- tumours (89\% versus 73\%, CI 95\% 1.1-6.2; $p<0.01$ ) [21]. Chia et al analysed 2026 patients with lymph node negative breast cancer, of which $10.2 \%$ were HER-2+. In this cohort, the RFS at 10-years was lower for HER-2+ tumours when compared to HER-2- tumours $(65.9 \%$ versus $75.5 \%$ respectively $p=0.01)$. Nevertheless, the number of infracentimetric HER-2+ tumours in this cohort was small $(n=21)$. In 2009, Gonzalez et al published a retrospective series of 965 patients with T1ab tumours treated at the MD Anderson Cancer Centre from 1990-2002 whose patients did not receive treatment with adjuvant chemotherapy or trastuzumab. In this study, HER-2+ status was also strongly associated with a worse RFS at five years $(77.1 \%$ versus $93.7 \%$ p $<0.001)$ [9]. In addition, this study also had a validation cohort with 350 tumours from the Institute Jules Bordet and Leoben General Hospital which also suggested a lower RFS at five years for the HER-2+ tumours group (87\% versus $97 \% ; p=.043)$ [9]. At the end of the same year, Curigliano and collaborators published a series of 2130 T1ab breast cancer patients-150 (7\%) with HER-2+-looked at the prognostic role of HER-2 status for small tumours [25]. 
After 4.6 years of follow-up, HER-2 overexpression was associated with a relative risk of 2.4 (Cl 95\%, 0.9-6.5; p 0.09) for DFS at five years. Recently Vaz-Luis et al in a series with more than 4000 patients with T1abN0 tumours, 520 of which with HER-2+ disease, reported distant relapse at 5 years for patients not treated with chemotherapy or trastuzumab that did not exceed $7 \%$ [10]. Fehrenbacher et al examined the outcomes of 234 patients with HER-2+ T1ab tumours diagnosed between 2000 and 2006 and similarly the prognosis for the patients not treated with chemotherapy or trastuzumab $(n=171)$ was, in general, excellent, with rates of recurrence (distant and local recurrence free interval) in all subgroups of less than $10 \%$ at 5 years [22]. Tables 1 and 2 summarise the survival estimates of the different studies.

Table 1. Role of HER-2 in the prognosis for breast cancers of $\leq 1 \mathrm{~cm}$ with negative lymph nodes.

\begin{tabular}{|c|c|c|c|c|c|}
\hline Study & Population & $\begin{array}{c}\text { HER+ } \\
\text { (\% of population) }\end{array}$ & $\begin{array}{l}\text { Monitoring } \\
\text { (years) }\end{array}$ & $\begin{array}{l}\text { Adjuvant } \\
\mathrm{CT} / \mathrm{HT}\end{array}$ & $\begin{array}{l}\text { Outcome for the study } \\
\text { population } \\
\text { (HER-2+ versus HER-) }\end{array}$ \\
\hline $\begin{array}{l}\text { Press et al } 1997 \\
N=242(23)\end{array}$ & N0 (22.7\% T1ab) & $46(19 \%)$ & 6.8 & $\begin{array}{l}\text { No adjuvant } \\
\text { treatment }\end{array}$ & $\begin{array}{l}\text { RFS at two years: } \\
83 \text { versus } 94 \%(p<0.05)\end{array}$ \\
\hline $\begin{array}{l}\text { Joensuu et al } 2003 \\
N=852(21)\end{array}$ & $\begin{array}{l}\text { T1abc } \\
(36.7 \% \mathrm{~T} 1 \mathrm{ab})\end{array}$ & $69(12 \%)$ & 9.5 & $1 \%(\mathrm{CMF}) / 4 \%$ & $\begin{array}{l}\text { DDFS at nine years: } \\
73 \text { versus } 89 \%(p=0.0003)\end{array}$ \\
\hline $\begin{array}{l}\text { Tovey et al } 2009 \\
N=362(24)\end{array}$ & $\begin{array}{l}\mathrm{T} 1-2 \\
\mathrm{G} 1-2\end{array}$ & $22(6 \%)$ & 6.5 & $9 \% / 82 \%$ & $\begin{array}{l}\text { BCSS at five years: } \\
68 \text { versus } 96 \%(p<0.001)\end{array}$ \\
\hline $\begin{array}{l}\text { Chia et al } 2008 \\
N=2026(8)\end{array}$ & $\begin{array}{l}\text { T1-3 } \\
(210-16 \% \text { T1ab) }\end{array}$ & $206(10.2 \%)$ & 12.4 & $11 \% / 20 \%$ & $\begin{array}{l}\text { RFS at ten years } 65.9 \\
\text { versus } 75.5 \%(p=0.01)\end{array}$ \\
\hline $\begin{array}{l}\text { Curigliano et al } 2009 \\
N=2130(25)\end{array}$ & T1ab & $150(7 \%)$ & 4.6 & $27 \% / 59 \%$ & $\begin{array}{l}\text { DFS at five years: } \\
\text { RE+: } 92 \text { versus } 99 \% \\
(p=0.013) \\
\text { RE-: } 91 \text { versus } 92 \% \\
(p=0.09)\end{array}$ \\
\hline $\begin{array}{l}\text { Gonzalez-Ângulo et al } \\
2009 \\
\mathrm{~N}=963 \text { (9) }\end{array}$ & T1ab & $98(10.1 \%)$ & 6.2 & $0 / 55 \%$ & $\begin{array}{l}\text { RFS at five years } 77.1 \% \\
\text { versus } 93.7 \%(p<0.001)\end{array}$ \\
\hline $\begin{array}{l}\text { Fehrenbacher et al } 2014 \\
N=234(22)\end{array}$ & T1ab & $234(100 \%)$ & 5.8 & $47.9 \% / 25.6 \%$ & $\begin{array}{l}\text { RFI at five years: } \alpha \\
\text { T1a: } 97.4 \% \\
\text { T1b: } 90.9 \%\end{array}$ \\
\hline $\begin{array}{l}\text { Vaz-Luis et al } 2014 \\
N=4113(10)\end{array}$ & $\mathrm{T} 1 \mathrm{ab}$ & $528(12.8 \%)$ & 5.5 & $75.5 \% / 17.1 \%$ & $\begin{array}{l}\text { IDFS at five years:* } \\
\text { T1a: } 84-86 \% \text { versus } 86-93 \% \\
\text { T1b: } 68-86 \% \text { versus } 81-91 \% \\
\text { DRFS at five years:* } \\
\text { T1a: } 93-96 \% \text { versus } 93-98 \% \\
\text { T1b: } 94 \% \text { versus } 90-96 \%\end{array}$ \\
\hline
\end{tabular}

a Data available only for HER-2+ tumours

*Population which did not receive adjuvant trastuzumab/chemotherapy

Legend: BCSS = Breast cancer specific survival, DDFS = Distant disease-free survival, IDFS = Invasive disease-free survival; RFI = Recurrence-free interval; RFS = Recurrence-free survival; ER+ = Oestrogen receptor positive; ER- = Oestrogen receptor negative; $\mathrm{T}=$ Trastuzumab; $\mathrm{CT}=$ Chemotherapy; $\mathrm{N}=$ Number of patients; $\mathrm{N} 0$ = Negative lymph nodes, $\mathrm{T} 1 \mathrm{ab}: \leq 1 \mathrm{~cm}$; CMF: Cyclophosphamide, methotrexate, 5-fluorouracil. 
Table 2. Outcomes by treatment for T1abN0 HER2+ tumours.

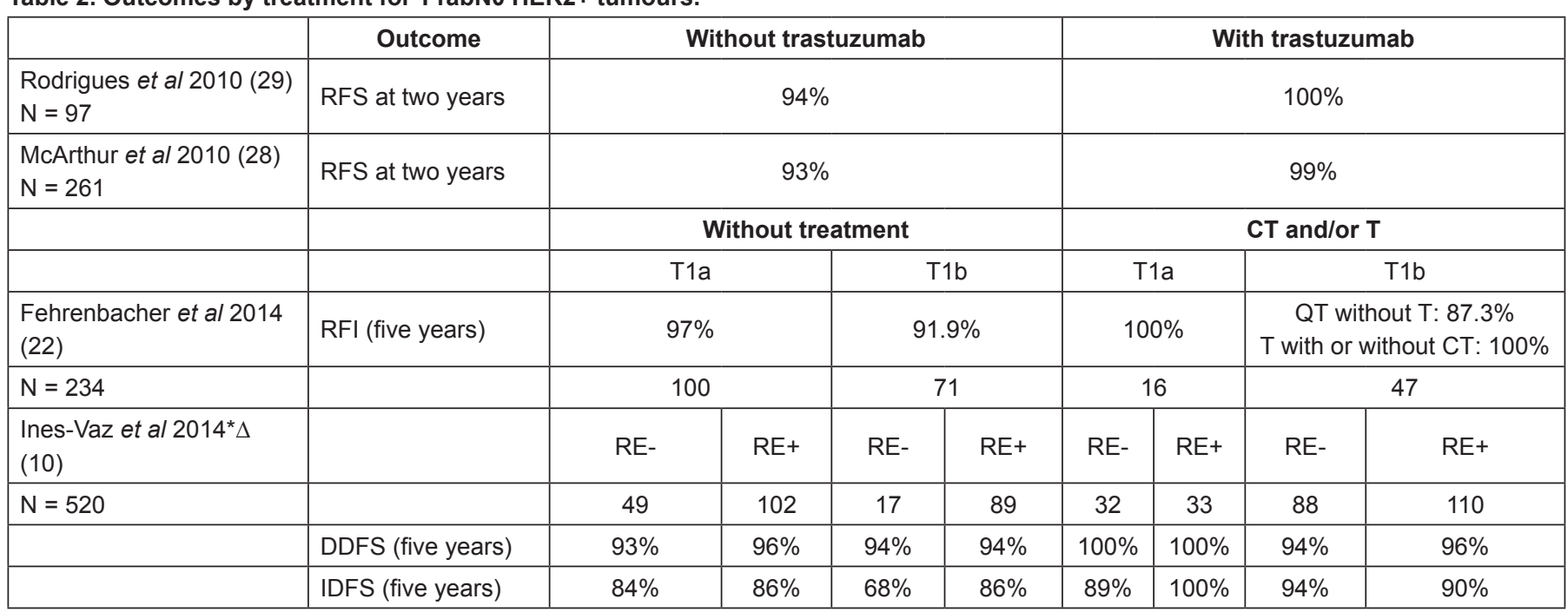

*T1a: $70.7 \%$ and $95.3 \%$ received trastuzumab and chemotherapy, respectively $\Delta \mathrm{T} 1 \mathrm{~b}: 60.5 \%$ and $98.4 \%$ received trastuzumab and chemotherapy, respectively Legend: DDFS = Distant disease free survival, IDFS = Invasive disease free survival; RFS = Recurrence free survival; ER+ = Oestrogen receptor positive; ER- = Oestrogen receptor negative; $\mathrm{T}=$ Trastuzumab; $\mathrm{CT}=$ Chemotherapy; $\mathrm{N}=$ Number of patients.

\subsection{Impact of hormone receptors on the prognosis for T1ab HER-2+ tumours}

The impact of the hormone receptors (HR) in the HER-2+ population has not yet been completely clarified. In the National Comprehensive Cancer Network (NCCN) series, T1b tumours had an invasive disease-free survival (IDFS) at 5 years of $68 \%$ (Cl 95\% 40-86\%) versus $86 \%$ (Cl 95\% 76-92\%) for HR+ T1b tumours [10]. In this same series the estimates of DDFS at 5 years were similar in the two groups, 94\% (Cl 95\%, 63-99\%) for patients with HR negative (HR-) T1b tumours not treated with chemotherapy/trastuzumab and $94 \%$ (Cl 95\%, 86-98\%) for patients with HR+ tumours. Of note, the wide confidence intervals reported in a cohort study reported by Chia et al on 117 patients with stage I HER-2+ breast cancer, the HR+ subgroup showed a higher RFS at 10 years (77.5\% versus $68.3 \%)$ [8]. Finally, the series published by Fehrenbacher covered a population of 234 patients of which $73.1 \%$ did not receive chemotherapy or trastuzumab, among those, the $138(59 \%)$ patients with HR+ tumours treated had a recurrence free interval (RFI) similar to the $96(41 \%)$ of patients with HR- tumours (94.9\% versus $95.1 \%$, respectively). Of note, $116(50 \%)$ patients had T1a tumours, which may have made the difference between the subgroups undetectable. In addition, the RFI for the HR- subgroup, when both the treated and untreated patients are analysed, was numerically lower (92.9\% versus 95\%) [22]. Globally these data indicate that the hormonal status may have a role in the prognosis for infracentimetric HER-2+ tumours, with some but not all series indicating unfavourable outcomes in HRpatients at five years.

\subsection{Impact of size on the prognosis for T1ab HER-2+ tumours}

In the article mentioned previously by Fehrenbacher, the invasive RFI at 5 years was 97\% (Cl 95\%, 90.9-99.0\%), 91.9\% (Cl 95\%, 81.5-96.6\%), and $89.4 \%(\mathrm{Cl} 95 \%, 70.6-96.5 \%)$ for $\mathrm{T} 1 \mathrm{a}, \mathrm{T} 1 \mathrm{~b}$, and $\mathrm{T} 1 \mathrm{~b}=1 \mathrm{~cm}$ tumours, respectively [22]. These data are in line with the findings of Verscraegen et al who reported a logarithmic linear relationship between tumour size and death due to breast cancer, espe-cially for small tumours [26]. The Vaz-Luis et al series also suggested that the tumour size can influence the risk of recurrence [10]. 


\section{Impact of treatment with chemotherapy and/or trastuzumab on T1ab HER-2+ tumours}

Data derived from retrospective studies seems to demonstrate a benefit from adjuvant treatment based on trastuzumab in this population. The NCCN series examined survival estimates in treated and non-treated groups with chemotherapy and trastuzumab. Although the design of the study does not permit formal comparisons between the groups, the patients with T1a tumours who received treatment (chemotherapy and/or trastuzumab), had IDFS values at five years of $89-100 \%$ and DDFS values of $100 \%$. For the T1b tumours, the IDFS was $90-94 \%$ and the DDFS was $94-96 \%$ for the treated patients versus an IDFS at five years of $68-86 \%$ and a DDFS of $94 \%$ for the untreated patients [10] (Table 2).

A single-centre study at the Memorial Sloan-Kettering Cancer Centre reported a three-years DDFS of 97\% (CI 95\%, 92-100\%) in a group of 45 patients not treated with trastuzumab and of $100 \%$ in a group of 54 patients treated with trastuzumab [27, 28].

In addition, another retrospective study of the Institut Curie (Paris, France) included 97 patients with tumours smaller than or equal to $1 \mathrm{~cm}$ between 2002 and 2008, all without lymph node involvement. Adjuvant trastuzumab based therapy was given to patients considered to have a high risk profile-HR-, high grade or high mitotic index according to institutional criteria. Of the 97 T1abN0 HER-2+ patients, 41 $(42 \%)$ received trastuzumab and $93 \%$ of these also received chemotherapy. None of the patients treated with anti-HER-2 therapy had a recurrence, while $9 \%$ of those who did not receive adjuvant treatment with trastuzumab had recurrence $(5 / 56-4$ of the recurrences in the subgroup with negative hormone receptors) $(p=0.11)[29]$.

A meta-analysis presented at the ASCO Annual Meeting 2014 was performed to estimate overall survival (OS) and DFS with the addition of adjuvant trastuzumab for tumours $\leq 2 \mathrm{~cm}$, independently of lymph node status, using five randomized clinical trials published between 2004 and 2013. Of the 11,200 patients randomised in these five studies, 4220 fulfilled the criteria for tumour size (2588 were randomized to receive trastuzumab and 1632 not). The majority of the study population was composed of T1c tumours and had lymph node involvement. Two cohorts were analysed according to HR status. The two cohorts showed a reduction in relative risk of $30 \%$ $(\mathrm{HR}=0.7, \mathrm{Cl} 95 \% 0.58-0.85)$ for the group receiving trastuzumab. The HR+ patient cohort showed a cumulative recurrence rate at eight years which was $7 \%$ lower for the treatment arm $(24.3 \%$ versus $17.3 \%, p<0.001)$, and a cumulative mortality rate $3.8 \%$ lower $(11.8 \%$ versus $7.8 \%, p=0.005)$. Restricting the data to the $\mathrm{N} 0 / 1$ patients, the benefit persists in the reduction of recurrence (19.4\% versus $12.7 \%, p=0.005)$ and the mortality rate at eight years $(7.4 \%$ versus $5.3 \%, p=0.12)$, although the latter is not statistically significant. The data for the HR- patient cohort is similar, such that the trastuzumab arm showed a recurrence and mortality rate at eight years which was lower than the arm without the treatment $(33.4 \%$ versus $24 \%, p<0.001$ and 21.2 versus $12.4 \%, p=0.001$ respectively). In this meta-analysis, it is important to point out that the vast majority of the patients had T1c tumours and lymph node involvement. Similar benefits were found independently of HR, however the pattern of recurrence seemed to be different according to the HR expression, with the HR-subgroup having a higher risk of early relapse [30].

Globally these studies suggest that although these tumours generally have a very good prognosis without treatment and, in fact, in the majority of cases favourable outcomes can be expected without cytostatic or anti-HER-2 therapy, there are some patients who may benefit from treatment with chemotherapy and trastuzumab. As anticipated, classic factors for prognosis such as HR status and size seem to have an impact on the prognosis and may inform the treatment decision. For these patients, a cautious balance of benefits and toxicity should be weighed. The absolute benefit in the majority of cases was less than $5 \%$ in the reduction of the risk of distant recurrence. This is in fact the ideal context for developing less intense and toxic treatments.

A recent single-arm, multicentric study conducted by the Dana-Farber Cancer Institute assessed the benefits of chemotherapy associated with trastuzumab in HER-2+ patients with tumours less than or equal to $3 \mathrm{~cm}$ without lymph node involvement. DFS was the primary outcome. The treatment regimen consisted of weekly paclitaxel - $80 \mathrm{mg} / \mathrm{m}^{2}$ - for 12 weeks associated with 3-weekly trastuzumab which was continued for one year of treatment (TH regimen). Nearly $50 \%$ of a total of the 406 patients recruited had tumours with $1 \mathrm{~cm}$ or less and $91 \%$ of these had tumours with $2 \mathrm{~cm}$ or less. The results obtained after 3.6 years of follow-up showed a DFS of 98.7\% (CI 95\%, 97.6-99.8; $p<0.01)$ [31]. The data from this study was practice changing, leading to an update on several guidelines, such as the NCCN guidelines and the St Gallen consensus which now recommend this regimen for patients with small node negative HER-2+ tumours (Table 3). 
Table 3. Prospective studies for HER-2+ breast tumours.

\begin{tabular}{|c|c|c|c|c|c|c|c|c|}
\hline \multicolumn{4}{|c|}{ Study Characteristics } & \multicolumn{3}{|c|}{ Population } & \multicolumn{2}{|c|}{ Outcomes } \\
\hline Study & N/CT Model & Phase & $\begin{array}{c}\text { Monitoring } \\
\text { (years) }\end{array}$ & Inclusion & $\begin{array}{c}\% \text { LFN } \\
\text { negative }\end{array}$ & $\%<1 \mathrm{~cm}$ & DFS & ICC* \\
\hline $\begin{array}{l}\text { N9831 + B-31 } \\
\text { Perez et al, } \\
2011(12)\end{array}$ & $\begin{array}{l}\text { A: } 2028 / A C-T H \\
\text { B: } 2017 / A C-T\end{array}$ & III & 3.9 & $\begin{array}{l}>1 \mathrm{~cm} \text { if ER - } \\
>2 \mathrm{~cm} \text { if ER + }\end{array}$ & $5.7 \%$ & $0 \%$ & $\begin{array}{c}\text { A: } 85.8 \% \\
\text { (four years) } \\
\text { B: } 75.8 \%\end{array}$ & $3.3-3.8 \%$ \\
\hline $\begin{array}{l}\text { HERA } \\
\text { Goldhirsch et al, } \\
2013 \text { (43) }\end{array}$ & $\begin{array}{l}\text { A: } 1552 / A C-T H \\
\text { B: } 1697 / A C-T\end{array}$ & III & 8 & $\begin{array}{c}>1 \mathrm{~cm} \text { if LFN } \\
\text { negative } \\
\text { Or positive } \\
\text { lymph nodes }\end{array}$ & $32.5 \%$ & NR & $\begin{array}{c}85.8 \% \\
\text { (two years) }\end{array}$ & $1.7 \%$ \\
\hline $\begin{array}{l}\text { BCIRG-006 } \\
\text { Slamon et al, } \\
2011 \text { (15) }\end{array}$ & $\begin{array}{l}\text { A: } 1073 / \mathrm{ACT} \\
\text { B: } 1074 / \mathrm{AC}-\mathrm{TH} \\
\mathrm{C}: 1075 / \mathrm{TCH}\end{array}$ & III & 5.4 & Any size & $28.6 \%$ & $4.6 \%$ & $\begin{array}{c}84 \% \\
\text { (five years) } \\
93 \% \text { if } \mathrm{T}<1 \mathrm{~cm} \\
(\text { ACTH })\end{array}$ & $\begin{array}{c}2 \% \\
\text { (up to } 4 \% \text { ) }\end{array}$ \\
\hline $\begin{array}{l}\text { Tolaney et al, } 2015 \\
\text { (31) }\end{array}$ & 406/TH & II & 3.6 years & $\begin{array}{c}\leq 3 \mathrm{~cm} \\
(50 \% \leq 1 \mathrm{~cm})\end{array}$ & $\begin{array}{c}\sim 99 \% \\
\text { (six patients } \\
\text { with N1mi) }\end{array}$ & $50 \%$ & $\begin{array}{c}98.7 \% \\
\text { (three years) }\end{array}$ & $0.5 \%$ \\
\hline
\end{tabular}

Legend: AC: Doxorubicin, cyclophosphamide; TH: Concomitant taxane, trastuzumab; TH: Sequential; CCI: Congestive cardiac insufficiency (Grades III and IV); LFN = Lymph nodes; DFS: Disease free survival; CT = Chemotherapy; N1mi = Microscopic involvement; NR: Not reported; ER+ = Oestrogen receptor positive; ER- = Oestrogen receptor negative.

\section{Toxicity associated with systemic treatment}

When we think about adjuvant treatment of breast cancer, it is fundamental that the benefits outweigh the risks of severe toxicity in the short and long term. Trastuzumab related cardiotoxicity presents most frequently with an asymptomatic reduction in the left ventricular ejection fraction, and rarely with symptomatic congestive heart failure. In contrast to anthracyclines, this does not seem to be related to the cumulative dose as it is normally reversible with the discontinuation of treatment, which permits an attempt to reintroduce the drug following recovery [32-34].

Trastuzumab is associated with a low incidence of severe (grade III or IV) cardiotoxicity with a reported incidence among the several studies which can reach $4 \%$, when trastuzumab was used, against $1.3 \%$ in regimens which did not use this drug. In a meta-analysis of eight studies which included 11,991 patients, the use of trastuzumab was associated with an increase in the risk of cardiac failure by five times and reduction in the left ventricular ejection fraction by about two times [35]. On the other hand, the incidence of class III and IV cardiac failure seems to be significantly lower in the patients who did not receive anthracyclines as shown in the BCIRG $006-0.4 \%$ for the TCH (docetaxel, carboplatin, and trastuzumab) regimen versus $2-4 \%$ for those who received anthracyclines (AC followed by paclitaxel and trastuzumab).

The patients included in the trastuzumab adjuvant studies were relatively young and cardiac disease was an exclusion criteria. The risk of cardiotoxicity for the general population is therefore greater [36-39]. For example, in a retrospective analysis including 442 patients treated with anthracyclines and trastuzumab, the cumulative incidence of cardiac failure/cardiomyopathy reached $20.1 \%$ in five years [37]. In addition to cardiotoxicity, other toxicities related to chemotherapy such as neuropathy, leukaemia, and death should also be considered as well as the non-negligible risk of hospitalisation in the context of chemotherapy [40].

The TH regimen showed an excellent safety profile in the study by Tolaney et al. Only two patients $(0.5 \%)$ showed grade III cardiotoxicity (cardiac failure), which was reversed in both following the interruption of the treatment with trastuzumab. Another 13 patients (3.5\%) developed an asymptomatic reduction of the ejection fraction with recovery to normal levels in 11 of these cases. No death related to the treatment was reported [31]. 
Clinical trials which identify regimens with a more favorable toxicity profile are necessary in order to maximize the cost-benefit ratio of adjuvant treatments in this subgroup of patients. Clinical trials such at ATEMPT (TDM1 versus paclitaxel/trastuzumab for breast; NCT01853748) and RESPECT (assessment of trastuzumab without chemotherapy as a postoperative adjuvant treatment for breast cancer in HER-2+ patients; NCT01104935) are examples of trials exploring the activity of less toxic regimens. Other strategies, such as dual anti-HER-2 blocking or anti-HER-2 agents associated with endocrine treatment are being evaluated.

\section{Discussion}

Since 2005, several randomized multicentric prospective clinical trials have established trastuzumab in combination with chemotherapy as the standard treatment for HER-2+ early breast cancer, demonstrating substantial gains in DFS and OS [11-15]. Nonetheless, most of these studies included patients with positive lymph nodes, and the majority excluded infracentrimetric tumours. The data derived from these studies was analyzed in a 2007 meta-analysis, which demonstrated a reduction of approximately $50 \%$ in the risk of recurrence and mortality, independent of lymph node status [41]. In addition, the benefit from trastuzumab was observed in all stages. In a subgroup analysis, T1c tumours without lymph node involvement showed benefits of the same magnitude in relation to the other high-risk groups from the addition of trastuzumab to adjuvant chemotherapy [12,13,42]. Thus, assuming a 50\% reduction in the risk of recurrence using chemotherapy plus trastuzumab for the T1ab population, the benefit of treatment would be directly related to the absolute risk of recurrence.

In the studies presented in this article, a risk of recurrence which varies with size and HR is currently estimated. Here we reviewed several papers which suggest that size and HR also play a role in the risk of recurrence among patients with infracentimetric tumours. In addition, HR status seems to differentiate between two distinct subgroups in terms of the risk of recurrence. Thus, and according to the recommendations of the NCCN, there will be patients with tumours of less than $1 \mathrm{~cm}$ (in addition to those with larger tumours and HR-) who can benefit from chemotherapy plus trastuzumab. Figure 1 shows a possible treatment algorithm for these patients.

The recently published prospective study by Tolaney et al shows that in a cohort of patients with HER-2+ tumours of up to $3 \mathrm{~cm}$, the survival rate at three years following treatment with the TH regimen was excellent with a favorable toxicity profile [31]. Therefore TH seems the best regimen to be used among patients with infracentimetric HER2+ tumours who we decide to treat.

The decision to prescribe adjuvant treatment based on trastuzumab should then weigh the toxicities inherent to this treatment, seeking to minimise the risks, and the possible absolute benefit deriving from this treatment for this population which has a low risk of recurrence. Prospective studies are difficult to develop and recruit in this scenario, thus it is essential to clarify the actual benefit for these patients.

\begin{tabular}{|c|c|c|}
\hline $\begin{array}{l}\text { Hormone } \\
\text { Receptor }\end{array}$ & $0.1-0.5 \mathrm{~cm}$ & $0.6-1.0 \mathrm{~cm}$ \\
\hline
\end{tabular}

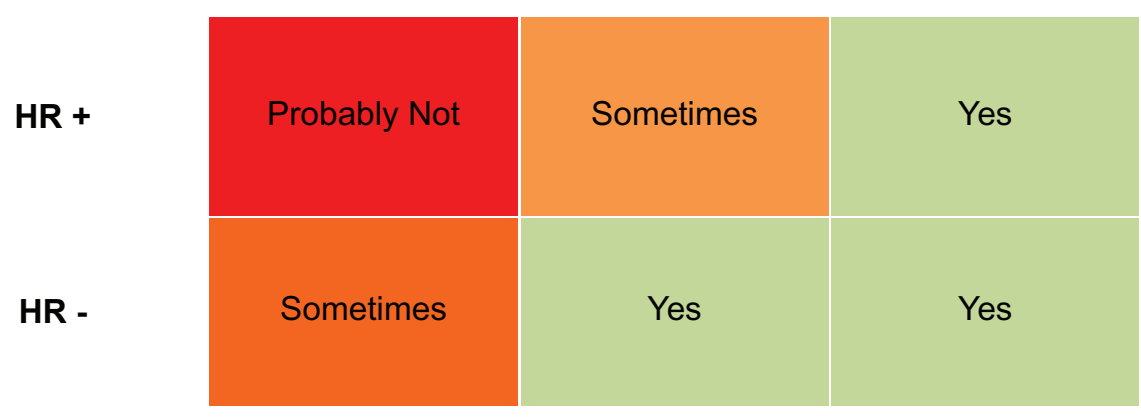

Figure 1. Suggestion for adjuvant therapy in Small Her-2+ Breast Cancer. Legend: HR+: Hormone receptor positive, HR-: Hormone receptor negative. 


\section{Conclusion}

Overall, the prognosis of patients with small $(<1 \mathrm{~cm})$ HER-2+ breast cancer is excellent. However in some selected cases the use of chemotherapy and/or targeted therapy may provide additional benefit. The therapeutic decision should always include a careful assessment of the risk-benefit ratio. Classical prognostic factors (e.g., size, nodal status, hormone receptor status) matter even in the setting of small tumours. Since this is a population with high survival rates the absolute benefit of any additional systemic therapy will always be marginal. In this context, the major challenge in the near future is to develop less toxic treatment regimens.

\section{Conflict of interest}

All of the authors agree with the publication of the article and declare that there are no conflicts of interest of any kind.

\section{References}

1. Ferlay J SI et al (2013) GLOBOCAN 2012 v1.0 Cancer Incidence and Mortality Worldwide: IARC CancerBase

2. National Cancer Institute (2014) SEER Cancer Statistics Review 1975-2012 Howlader N NA, Krapcho M, Garshell J, Miller D, Altekruse SF, Kosary CL, Yu M, Ruhl J, Tatalovich Z, Mariotto A, Lewis DR, Chen HS, Feuer EJ, Cronin KA (eds)

3. Kennedy $\mathrm{T}$ et al (2007) Treatment trends and factors associated with survival in T1aNO and T1bNO breast cancer patients Ann Surg Oncol 14(10) 2918-27 DOI: 10.1245/s10434-007-9441-5 PMID: 17638060

4. Schootman M et al (2004) The full potential of breast cancer screening use to reduce mortality has not yet been realized in the United States Breast Cancer Res Treat 85(3) 219-22 DOI: 10.1023/B:BREA.0000025410.41220.67 PMID: 15111759

5. Borg A et al (1990) HER-2/neu amplification predicts poor survival in node-positive breast cancer Cancer Res 50(14) 4332-7 PMID: 1973070

6. Buzdar AU et al (2005) Significantly higher pathologic complete remission rate after neoadjuvant therapy with trastuzumab, paclitaxel, and epirubicin chemotherapy: results of a randomized trial in human epidermal growth factor receptor 2-positive operable breast cancer J Clin Oncol 23(16) 3676-85 DOI: 10.1200/JCO.2005.07.032 PMID: 15738535

7. Slamon DJ et al (1987) Human breast cancer: correlation of relapse and survival with amplification of the HER-2/neu oncogene Science 235(4785) 177-82 DOI: 10.1126/science.3798106 PMID: 3798106

8. Chia S et al (2008) Human epidermal growth factor receptor 2 overexpression as a prognostic factor in a large tissue microarray series of node-negative breast cancers J Clin Oncol 26(35) 5697-704 DOI: 10.1200/JC0.2007.15.8659 PMID: 19001334

9. Gonzalez-Angulo AM et al (2009) High risk of recurrence for patients with breast cancer who have human epidermal growth factor receptor 2-positive, node-negative tumors $1 \mathrm{~cm}$ or smaller J Clin Oncol 27(34) 5700-6 DOI: 10.1200/JCO.2009.23.2025 PMID: 19884543 PMCID: 2792998

10. Vaz-Luis I (2014) Outcomes by tumor subtype and treatment pattern in women with small, node-negative breast cancer: a multi-institutional study J Clin Oncol 32(20) 2142-50 DOI: 10.1200/JCO.2013.53.1608 PMID: 24888816 PMCID: 4076026

11. Joensuu $\mathrm{H}$ et al (2006) Adjuvant docetaxel or vinorelbine with or without trastuzumab for breast cancer $N$ Engl $J$ Med 354 809-20 DOI: 10.1056/NEJMoa053028 PMID: 16495393

12. Perez EA et al (2011) Four-year follow-up of trastuzumab plus adjuvant chemotherapy for operable human epidermal growth factor receptor 2-positive breast cancer: joint analysis of data from NCCTG N9831 and NSABP B-31 J Clin Oncol 29(25) 3366-73 DOI: 10.1200/JCO.2011.35.0868 PMID: 21768458 PMCID: 3164242

13. Piccart-Gebhart MJ et al (2005) Trastuzumab after adjuvant chemotherapy in HER2-positive breast cancer N Engl J Med 353(16) 1659-72 DOI: 10.1056/NEJMoa052306 PMID: 16236737 
14. Romond EH et al (2005) Trastuzumab plus adjuvant chemotherapy for operable HER2-positive breast cancer $N$ Engl J Med 353(16) 1673-84 DOI: 10.1056/NEJMoa052122 PMID: 16236738

15. Slamon D et al (2011) Adjuvant trastuzumab in HER2-positive breast cancer N Engl J Med 365(14) 1273-83 DOI: 10.1056/NEJMoa0910383 PMID: 21991949 PMCID: $\underline{3268553}$

16. Hanrahan EO (2007) Overall survival and cause-specific mortality of patients with stage T1a,bN0M0 breast carcinoma $J$ Clin Oncol 25(31) 4952-60 DOI: 10.1200/JCO.2006.08.0499 PMID: 17971593

17. Smart CR et al (1993) Insights into breast cancer screening of younger women. Evidence from the 14-year follow-up of the Breast Cancer Detection Demonstration Project Cancer 72 (4 Suppl) 1449-56 DOI: 10.1002/1097-0142(19930815)72:4+\&lt;1449: :AID-CNCR2820721406\&gt:3.0.CO:2-C PMID: 8339237

18. Tabar $L$ et al (1992) Breast cancer treatment and natural history: new insights from results of screening Lancet 339(3790) 412-4 DOI: 10.1016/0140-6736(92)90090-P PMID: 1346670

19. Allred DC et al (1992) HER-2/neu in node-negative breast cancer: prognostic significance of overexpression influenced by the presence of in situ carcinoma J Clin Oncol 10(4) 599-605 PMID: 1548522

20. Gusterson BA et al (1992) Prognostic importance of c-erbB-2 expression in breast cancer. International (Ludwig) Breast Cancer Study Group J Clin Oncol 10(7) 1049-56 PMID: 1351538

21. Joensuu $\mathrm{H}$ et al (2003) Amplification of erbB2 and erbB2 expression are superior to estrogen receptor status as risk factors for distant recurrence in PT1N0MO breast cancer: a nationwide population-based study Clin Cancer Res 9(3) 923-30 PMID: 12631589

22. Fehrenbacher $\mathrm{L}$ et al (2014) Distant invasive breast cancer recurrence risk in human epidermal growth factor receptor 2-positive T1a and T1b node-negative localized breast cancer diagnosed from 2000 to 2006: a cohort from an integrated health care delivery system J Clin Oncol 32(20) 2151-8 DOI: 10.1200/JC0.2013.52.0858 PMID: 24888815

23. Press MF et al (1997) HER-2/neu gene amplification characterized by fluorescence in situ hybridization: poor prognosis in node-negative breast carcinomas J Clin Oncol 15(8) 2894-904 PMID: 9256133

24. Tovey SM et al (2009) Poor survival outcomes in HER2-positive breast cancer patients with low-grade, node-negative tumours Br J Cancer 100(5) 680-3 DOI: 10.1038/sj.bjc.6604940 PMID: 19223897 PMCID: 2653773

25. Curigliano $\mathrm{G}$ et al (2009) Clinical relevance of HER2 overexpression/amplification in patients with small tumor size and nodenegative breast cancer J Clin Oncol 27(34) 5693-9 DOI: 10.1200/JCO.2009.22.0962 PMID: 19884553

26. Verschraegen $C$ et al (2005) Modeling the effect of tumor size in early breast cancer Ann Surg 241(2) 309-18 DOI: $10.1097 / 01$. sla.0000150245.45558.a9 PMID: 15650642 PMCID: 1356917

27. McArthur HL MP et al (2009) Benefits of trastuzumab-based therapy for women with small, node-negative, HER2-positive breast cancer ASCO Breast Cancer Symposium (Abst 228)

28. McArthur HL MK et al (2010) Use of adjuvant trastuzumab with chemotherapy in women with small, node-negative, HER2-positive breast cancers ASCO Meeting Abstracts 28 (15_suppl) 615

29. Rodrigues MJ et al (2010) Trastuzumab treatment in t1ab, node-negative, human epidermal growth factor receptor 2-overexpressing breast carcinomas J Clin Oncol 28(28) e541-2 DOI: 10.1200/JCO.2010.29.7952 PMID: 20660834

30. O'Sullivan C BI et al (2014) Efficacy of adjuvant trastuzumab (T) compared with no $\mathrm{T}$ for patients (pts) with HER2-positive breast cancer and tumors $\leq \mathbf{2} \mathrm{cm}$ : A meta-analysis of the randomized trastuzumab trials $J$ Clin Oncol $325 \mathrm{~s}$ (suppl; abstr 508)

31. Tolaney SM et al (2015) Adjuvant paclitaxel and trastuzumab for node-negative, HER2-positive breast cancer N Engl J Med 372(2) 134-41 DOI: 10.1056/NEJMoa1406281 PMID: 25564897 PMCID: 4313867

32. Fiuza M (2009) Cardiotoxicity associated with trastuzumab treatment of HER2+ breast cancer Adv Ther 26 Suppl 1 S9-17 DOI: 10.1007/s12325-009-0048-z 
33. Martin M et al (2009) Minimizing cardiotoxicity while optimizing treatment efficacy with trastuzumab: review and expert recommendations Oncologist 14(1) 1-11 DOI: 10.1634/theoncologist.2008-0137 PMID: 19147689

34. Perez EA et al (2008) Cardiac safety analysis of doxorubicin and cyclophosphamide followed by paclitaxel with or without trastuzumab in the North Central Cancer Treatment Group N9831 adjuvant breast cancer trial J Clin Oncol 26(3) 1231-8 DOI: 10.1200/JCO.2007.13.5467 PMID: $\underline{18250349}$ PMCID: $\underline{4048960}$

35. Moja L et al (2012) Trastuzumab containing regimens for early breast cancer Cochrane Database Syst Rev 4 CD006243

36. Bonifazi M et al (2013) Trastuzumab-related cardiotoxicity in early breast cancer: a cohort study Oncologist 18(7) 795-801 DOI: 10.1634/theoncologist.2013-0065 PMID: 23823908 PMCID: $\underline{3720632}$

37. Bowles EJ et al (2012) Risk of heart failure in breast cancer patients after anthracycline and trastuzumab treatment: a retrospective cohort study J Natl Cancer Inst 104(17) 1293-305 DOI: 10.1093/jnci/djs317 PMID: 22949432 PMCID: $\underline{3433392}$

38. Chavez-MacGregor M et al (2013) Trastuzumab-related cardiotoxicity among older patients with breast cancer $J$ Clin Oncol 31(33) 4222-8 DOI: 10.1200/JCO.2013.48.7884 PMID: 24127446 PMCID: 3821011

39. Chen $\mathrm{J}$ et al (2012) Incidence of heart failure or cardiomyopathy after adjuvant trastuzumab therapy for breast cancer $J$ Am Coll Cardiol 60(24) 2504-12 DOI: 10.1016/j.jacc.2012.07.068 PMID: 23158536

40. Hassett MJ et al (2006) Frequency and cost of chemotherapy-related serious adverse effects in a population sample of women with breast cancer J Natl Cancer Inst 98(16) 1108-17 DOI: 10.1093/jnci/djj305 PMID: 16912263

41. Viani GA et al (2007) Adjuvant trastuzumab in the treatment of her-2-positive early breast cancer: a meta-analysis of published randomized trials BMC Cancer 7153 DOI: 10.1186/1471-2407-7-153 PMID: 17686164 PMCID: 1959236

42. Untch $\mathrm{M}$ et al (2008) Estimating the magnitude of trastuzumab effects within patient subgroups in the HERA trial Ann Oncol 19(6) 1090-6 DOI: 10.1093/annonc/mdn005 PMID: 18296421

43. Goldhirsch A (2013) 2 years versus 1 year of adjuvant trastuzumab for HER2-positive breast cancer (HERA): an open-label, randomised controlled trial Lancet 382(9897) 1021-8 DOI: 10.1016/S0140-6736(13)61094-6 PMID: 23871490 